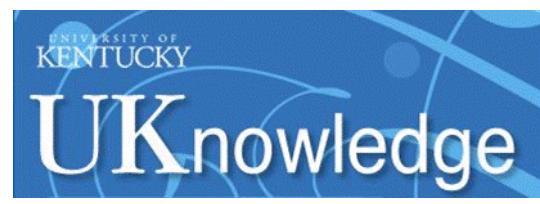

University of Kentucky

UKnowledge

\title{
Effectiveness of a Home-Based Eccentric-Exercise Program on the Torque-Angle Relationship of the Shoulder External Rotators: A Pilot Study
}

Timothy L. Uhl

University of Kentucky, tluhl2@uky.edu

Thomas Rice

Louisiana Tech University

Brianna M. Papotto

University of Kentucky, brianna.papotto@uky.edu

Timothy A. Butterfield

University of Kentucky, tim.butterfield@uky.edu

Follow this and additional works at: https://uknowledge.uky.edu/rehabsci_facpub

Part of the Rehabilitation and Therapy Commons

Right click to open a feedback form in a new tab to let us know how this document benefits you.

\section{Repository Citation}

Uhl, Timothy L.; Rice, Thomas; Papotto, Brianna M.; and Butterfield, Timothy A., "Effectiveness of a HomeBased Eccentric-Exercise Program on the Torque-Angle Relationship of the Shoulder External Rotators: A Pilot Study" (2017). Physical Therapy Faculty Publications. 66.

https://uknowledge.uky.edu/rehabsci_facpub/66

This Article is brought to you for free and open access by the Physical Therapy at UKnowledge. It has been accepted for inclusion in Physical Therapy Faculty Publications by an authorized administrator of UKnowledge. For more information, please contact UKnowledge@lsv.uky.edu. 


\section{Effectiveness of a Home-Based Eccentric-Exercise Program on the Torque-Angle Relationship of the Shoulder External Rotators: A Pilot Study}

Digital Object Identifier (DOI)

https://doi.org/10.1123/jsr.2017-0020

Notes/Citation Information

Published in Journal of Sport Rehabilitation, v. 26, issue 2, p. 141-150.

(C) 2017 Human Kinetics, Inc.

The copyright holder has granted the permission for posting the article here.

The document available for download is the authors' post-peer-review final draft of the article. 


\section{Effectiveness of a Home-based Eccentric Exercise Program on the Torque-Angle Relationship of the Shoulder External Rotators: A Pilot Study}

Timothy L. Uhl ${ }^{1,2}$ Thomas Rice ${ }^{3}$ Brianna Papotto ${ }^{1}$ Timothy A. Butterfield ${ }^{1,2,4}$

1. Department of Rehabilitation Sciences, Division of Athletic Training, University of Kentucky

2. Center for Muscle Biology, University of Kentucky, Lexington, KY

3. Department of Athletics, Louisiana Tech University, Rushton, LA

4. Department of Physiology, University of Kentucky, Lexington, KY

Corresponding author.

Timothy A Butterfield, PhD ATC

Department of Rehabilitations Sciences

University of Kentucky

Lexington, KY 40536-0200

859-218-0840

tim.butterfield@uky.edu 


\section{ABSTRACT}

3 Context: The role of the rotator cuff is to provide dynamic stability to the glenohumeral

4 joint. Human and animal studies have identified sarcomereogenesis as an outcome of

5 eccentric training indicated by more torque generation with the muscle in a lengthen

6 position.

7 Objective: We hypothesize that a home-based eccentric exercise program can increases

8 the shoulder external rotators eccentric strength at terminal internal rotation.

9 Design: Prospective case series.

10 Setting: Clinical laboratory and home exercising.

11 Participants: 10 healthy subjects (age $=30 \pm 10$ years)

12 Intervention: All participants performed two eccentric exercises targeting the posterior

13 shoulder for 6 weeks using a home based intervention program using side-lying external

14 rotation and horizontal abduction.

15 Main Outcome Measures: Dynamic eccentric shoulder strength measured at $60 \% \mathrm{sec}$

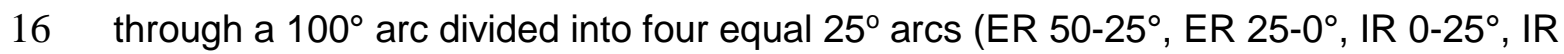

$1725-50^{\circ}$ ) to measure angular impulse to represent the work performed. Additionally,

18 isometric shoulder external rotation was measured at 5 points throughout the arc of

19 motion ( $45^{\circ} \mathrm{IR}, 30^{\circ} \mathrm{IR}, 15^{\circ} \mathrm{IR}, 0^{\circ}$, and $\left.15^{\circ} \mathrm{ER}\right)$. Comparison of isometric and dynamic

20 strength from pre to post testing was evaluated with a repeated measure ANOVA using

21 time and arc or positions as within factors.

22 Results: The isometric force measures revealed no significant differences between the

23 five positions $(P=0.56$, Table 1$)$. The dynamic eccentric data analysis revealed a

24 significant difference between $\operatorname{arcs}(P=0.02)$. The arc of Internal Rotation 25-50

25 percent change score was found to be significantly greater than the arc of Internal

26 Rotation $0-25^{\circ}(P=0.007)$. 
28 Conclusion: Following eccentric training the only arc of motion that had a positive

29 improvement in the capacity to absorb eccentric loads was the arc of motion that

30 represented eccentric contractions at the longest muscle length. 
The innate function of skeletal muscle is determined by its cell structure (fiber

34 morphology) and how these cells are arranged (muscle architecture). Fortunately, the

35 plasticity of skeletal muscle permits modifications to morphology and architecture when

36 the fibers are subjected to altered biochemical and mechanical stress during exercise-

37 induced loss of homeostasis. ${ }^{1}$ The subsequent architectural and structural adaptations

38 attenuate these stresses, thereby modifying fiber and muscle function. ${ }^{2,3}$ For example,

39 chronic training-induced fiber type transitions reduce the biochemical stresses produced

40 by cell metabolism, ${ }^{4}$ whereas fiber specific hypertrophy attenuates mechanical

41 stresses. ${ }^{5}$ Arguably, the most clinically recognizable exercise-induced adaptation in

42 skeletal muscle is hypertrophy, or the cumulative effect of increased muscle fiber size.

43 At the cellular level, muscle fibers can increase their size through mechanisms of

44 myofibrillogenesis and / or sarcomerogenesis.

45 Myofibrillogenesis is muscle fiber hypertrophy in the axial direction and increases

46 the cross sectional area of the fiber, because sarcomeres are added in parallel.

47 Sarcomeres are force producing elements, and the forces produced by them are additive

48 in parallel. Therefore, increases in muscle cross sectional area is a good predictor of

49 peak isometric force ${ }^{6}$ which is easily tested in the clinic and used as an objective criteria

50 for return to play following injury. ${ }^{7}$ Muscle fiber activation and the production of internal

51 forces are essential stimuli to optimize exercise-induced myofibrillogenesis. ${ }^{8-10}$

52 However, if a muscle fiber is also subjected to an external load that results in positive

53 strain or stretch of the fiber, hypertrophy will also occur in the longitudinal direction,

54 increasing fiber length due to sarcomerogenesis. ${ }^{11,12}$

55 Sarcomereogenesis, or the addition of sarcomeres in series within a muscle

56 fiber, has been studied extensively with in-vitro ${ }^{13,14}$, in-situ ${ }^{15,16}$ and in-vivo ${ }^{12,17-23}$

57 models. Although immobilizing a muscle in a lengthened position results in an increase 
58 in serial sarcomere number $21,22,24,25$ this addition is reversed if the stimulus is removed.

59 Subsequently, the lack of tension sensing in the sarcomeres returns the serial

60 sarcomere number to pre-stretch numbers within weeks, and demonstrates the plasticity

61 of sarcomere number and its relationship to joint angle, and muscle tension.

62 Serial sarcomere number within individual fibers demonstrates a high correlation

63 to joint angle ${ }^{26}$, and signifies a mechanical advantage produced through the gain of

64 sarcomeres in series. Increased serial sarcomere number would be of benefit in a static

65 contraction, improving the muscle function by shifting the force-length relationship to the

66 right, producing peak isometric force at a longer muscle length, or greater torque at a

67 greater joint angle. During a dynamic contraction, this would reduce sarcomere strain for

68 a given joint angle during eccentric contractions ${ }^{3,12}$. Further adaptations to function

69 would be manifested as increases in contractile velocity ${ }^{27}$, muscle power ${ }^{28}$, and

70 extensibility ${ }^{11}$. Clinically, this functional adaptation in serial sarcomere number may also

71 prevent injury when the muscle consistently works eccentrically at longer lengths ${ }^{11,22,29 .}$

72 These dynamic adaptations have been demonstrated in animal models using freely

73 walking rats ${ }^{20,23,30}$ and controlled eccentric exercise protocols in rabbits ${ }^{12,15,31}$.

$74 \quad$ The adaptation of sarcomere addition in series following chronic eccentric

75 exercise supports a previously proposed mechanism whereby sarcomere length is

76 optimized for the muscle length at which force exerted on the tendon is the greatest ${ }^{32}$.

77 Therefore this adaptation in serial sarcomere number has clinical implications as a

78 potential injury preventing mechanism, due to the shift of the force-length (torque-joint

79 angle) relationship to produce greater force (torque) at longer muscle lengths ${ }^{11}$.

80 Although sarcomere numbers have not been counted in human subjects following

81 eccentric exercise training, recent studies have demonstrated indirect evidence of

82 sarcomerogenesis in human subjects, including adaptations in muscle function ${ }^{33,34}$ and

83 morphology ${ }^{35,36}$ focused primarily on thigh ${ }^{35-39}$ and brachial ${ }^{34,35}$ muscles. To date, 
84 there are no data available as to the effectiveness of an eccentrically biased training

85 protocol on the function of the external rotators of the glenohumeral joint. Because these

86 muscles are integral to the deceleration of the humerus during throwing ${ }^{40}$, training

87 protocols that produce a rightward shift of the torque - joint angle relationship may prove

88 beneficial. Therefore, the purpose of this study was examine the effectiveness of a six

89 week home-based eccentric exercise program to enhance isometric and eccentric

90 external rotation strength in lengthened positions.

92 METHODS

93

94

\section{Setting and Participants}

99 university setting. (Age: $30 \pm 10 y e a r s$, Height: $164 \pm 10 \mathrm{~cm}$, Mass: $79 \pm 18 \mathrm{~kg}$ ). Subjects were

100 excluded from participation if they reported a history of shoulder or neck pathology,

101 previous shoulder or neck surgery, or shoulder or neck pain within the last 6 months. All

102 healthy subjects not excluded and willing to participate read and signed a University of

103 Kentucky Institutional Institutional Review Board approved informed consent prior to

104 participation in the study.

105 Subjects filled out the Penn Shoulder Score before testing to evaluate level of 106 shoulder function prior to participating. The Penn shoulder score ranges from 0-100 with

107100 representing highest level of function. The score has been found to be a reliable and 108 valid measure of shoulder function ${ }^{41}$. The Penn shoulder score averaged 97 with a range 109 (85 - 100) indicating that current participants demonstrated near normal function at the 110 onset of the study. All testing was completed at the Musculoskeletal Laboratory at the 111 University of Kentucky with a single unblinded investigator performing all testing. 


\section{Study Design}

This prospective case series investigation was designed to investigate the

116 effectiveness of home-based eccentric exercises for the posterior shoulder to improve

117 external rotation strength and improve ability of the posterior shoulder to absorb dynamic

118 internal rotation forces. Three days of familiarization with 1 week of rest between testing

119 episodes was used to establish baseline values and evaluate reliability of testing

120 procedures. A six-week exercise intervention incorporating 2 exercises was carried out

121 by all participants. The same testing procedures were repeated after the program to

122 evaluate changes from the intervention. Participants were asked to not start a new

123 exercise program during the study however they could continue to perform their normal

124 exercise and activities of daily living during the study. The independent variable is time

125 identified as pre-exercise and post-exercise tests. There are 2 dependent variables

126 (isometric torque at 5 angles and dynamic eccentric shoulder external rotation angular

127 impulse) that were measured at every time point.

\section{Isometric and Isokinetic Testing Procedures}

Prior to shoulder testing all participants completed 3 shoulder stretches (cross

132 body, sleeper stretch, corner wall shoulder stretch) for 2 sets of 30 seconds each.

133 Participants then warmed up with two active range of motion exercises with no load

134 consisting of side-lying external rotation and side-lying horizontal shoulder abduction and

135 adduction. Each exercise was performed for approximately one minute. The same

136 warm-up occurred prior to each day of testing.

137 Next, shoulder strength testing was performed using an isokinetic dynamometer

138 (Cybex Norm, Ronkonkoma, NY) as previously reported. ${ }^{42}$ Participants were seated

139 with their dominant shoulder in 60 degrees of abduction and 30 degrees of horizontal 
140 adduction. This was defined as the scapular plane in the Cybex Norm user's manual.

141 Both positions were confirmed using a hand held goniometer on all subjects. Isometric

142 testing was always performed first, isometric shoulder external rotation strength was

143 determined from the average of two trials taken at five test positions $\left(45^{\circ} \mathrm{IR}, 30^{\circ} \mathrm{IR}, 15^{\circ}\right.$

$144 \mathrm{IR}, 0^{\circ}$, and $\left.15^{\circ} \mathrm{ER}\right)$. The order of the test position was randomly assigned using a

145 random number generator with Microsoft Excel on each testing day in order to minimize

146 length change biases related to the length-dependent and time-dependent properties of

147 muscle. ${ }^{43,44}$

148 In each test position, subjects performed one sub-maximal practice repetition for

1493 seconds, rested for 20 seconds and then performed two maximal repetitions for 3-

150 seconds with a 60 second rest between each effort as previously established. ${ }^{33}$

151 Standardized verbal encouragement was given during isometric strength testing for

152 maximal repetitions to attempt to maximize the subject's effort and strength potential. ${ }^{45}$

153 Peak torque was recorded for both isometric contractions at every angle and averaged

154 to represent angle specific torque. The excellent reliability of these testing procedures

155 between days (ICC $\geq 0.85)$ has been previously reported. ${ }^{42}$

156 Following the collection of isometric torque data, dynamic eccentric shoulder

157 external rotation torque data were collected, while maintaining the shoulder in the same

158 test position and through a $100^{\circ}$ arc of motion from $50^{\circ}$ of external rotation to $50^{\circ}$ of

159 internal rotation. The continuous passive motion (CPM) mode was used with the Humac

160 software (Computer Sports Medicine Inc, Stoughton, MA) on the Cybex Norm with an

161 internal rotation velocity set at $60^{\circ} /$ second. From the start position of $50^{\circ}$ external

162 rotation, the subject was instructed to maximally contract into external rotation to initiate

163 internal rotation. The subject was instructed to maximally resist internal rotation through

164 the entire range of motion in order to evaluate dynamic eccentric external rotation torque

165 production. The subject was asked to relax his/her arm as the isokinetic dynamometer 
166 passively returned the arm into external rotation starting position at $15 \%$ second. This

167 process removed all concentric activity during testing. Participants were given three

168 minutes to rest following the familiarization phase and then performed six maximal

169 efforts in a row, with 7 seconds of recovery during the passive return to $50^{\circ}$ of external

170 rotation between trials. Standardized verbal encouragement was given during eccentric

171 testing. The middle four trials were averaged together to determine angular impulse later

172 used for data reduction and statistical analyses. A total of 3 baseline-testing sessions,

173 one week apart, were collected before initiating the home exercise eccentric program to

174 reduce the effect of motor learning during a novel task. ${ }^{46,47}$ Post-intervention testing

175 occurred at 6 weeks after the start of the home exercise program, and consisted of the

176 same procedures described above. The reliability of the dynamic eccentric shoulder

177 external rotation strength as determined by angular impulse is excellent (ICC $\geq 0.97)$ as

178 previously reported. ${ }^{42}$

\section{Exercise Procedures}

182 The home-based exercise program consisted of 2 eccentrically-biased exercises

183 consisting of side-lying horizontal adduction and side-lying external rotation. This

184 exercise protocol is modified from Blackburn et al., shown to be an excellent position to

185 activate the posterior shoulder musculature ${ }^{48}$. Participants were all given the same

186 exercise instructions for performing two sets of each exercise with 15 repetitions per set,

1874 times a week. In order to focus on the eccentric component of the exercise and

188 minimize the concentric portion, specific instructions were provided and initially

189 performed with investigator supervision. To bias the exercises for eccentric contractions,

190 subjects removed the weight from their own hand at the end of the eccentric contraction

191 phase, and rotated to a supine position to allow gravity to externally rotate the humerus 
192 back to the starting position to minimize concentric activity. They then placed the weight

193 back in the hand of the experimental side, and rotated back to side laying for the next

194 repetition. All participants had to demonstrate proper form with both eccentric exercise

195 maneuvers. Form was deemed proper when subjects could effectively eliminate

196 concentric contractions from both exercises regimens, and perform eccentric

197 contractions through the full range of motion at the correct speed as per the instructions

198 (Appendix). To support the clinical instruction, detailed written methods and pictures

199 were given to participants to take home (Appendix). All eccentric exercises were

200 performed at a slow pace of eight seconds for lowering the weight to emphasize the

201 eccentric load to the posterior rotator cuff. Participants returned weekly to progress their

202 resistance loads and assure proper exercise form.

203 Starting resistance for the eccentric exercise was determined from the highest

204 dynamic eccentric shoulder external rotation average peak torque generated on one of

205 the 3 baseline testing days. Average peak torque $(\mathrm{Nm})$ was divided by the length of the

206 subject's forearm $(m)$ to estimate the force $(N)$, which was then converted to pounds and

207 multiplied by 0.2 to determine the weight used for the first week of training. Subjects

208 were progressed on a weekly basis using a linear progression of increasing loads while

209 repetitions were held constant. After the first week, the initial load was increased 20\%

210 and then subsequently increased by $25 \%$ weekly for the next 5 training weeks. Subjects

211 were given a log to track their weight, sets, and repetitions that was returned at the end

212 of the study. Additionally, a modified Borg perceived exertion scale was used to record

213 level of difficulty when performing exercise. The scale ranged from 0-10 with 10

214 representing maximal effort during an exercise. This allowed the researchers to monitor

215 exercise progress so that resistance loads could match perceived exertion during

216 exercise. 


\section{Data Reduction and Statistical Analysis}

The two isometric trials for each day of testing were averaged together to

221 represent external rotation torque at each shoulder angle. The post-exercise test data

222 were subtracted from the pre-exercise test data for each subject to determine the

223 change score. Shapiro-Wilk test for normality revealed that the isometric data were not

224 normally distributed. Non-Parametric analysis was carried out using Friedman test to

225 determine if change scores differed across the five positions (IR $45^{\circ}, \mathrm{IR} 30^{\circ}, \mathrm{IR} 15^{\circ}$,

226 Neutral, ER $15^{\circ}$ ) for isometric data with alpha level set at $P \leq 0.05$. Wilcoxon Signed

227 Rank Test was used to compare individual differences between positions if appropriate,

228 with alpha level corrected for ten comparisons $(P \leq 0.005)$.

229 Raw data from each dynamic eccentric testing day for each subject were

230 extracted from the Cybex. The raw data provided time, speed, angle and torque at a rate

231 of $100 \mathrm{~Hz}$. These data were imported into an excel (Microsoft, Redwood CA) template to

232 calculate angular impulse. Angular impulse was calculated using the trapezoidal

233 equation for area $\left\{\Sigma\left(1 / 2[\theta \text { at point } A+\text { torque at point } B]^{\star} .01\right)\right\}$ for entire trial. The four

234 middle efforts of the 6 trials were averaged together. The average total angular impulse

235 was further divided into 4 equal $25^{\circ}$ arcs of motion to clearly represent work production

236 through the range of motion. The post-exercise test data were subtracted from the pre-

237 exercise test data for each subject to determine the change score. Shapiro-Wilk test for

238 normality revealed that the dynamic eccentric data were not normally distributed. Non-

239 Parametric analysis was carried out using Friedman test to determine if change scores

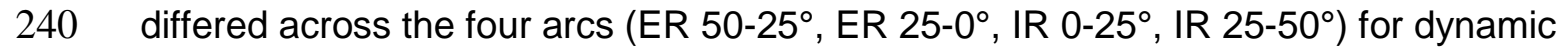

241 eccentric data with alpha level set at $\mathrm{P} \leq 0.05$. Wilcoxon Signed Rank Test was used to

242 compare individual differences between arcs if appropriate, with alpha level corrected for

243 six comparisons $(P \leq 0.0083)$. 


\section{RESULTS}

246

247

248

249 differences between the five positions $(P=0.56$, Table 1$)$. The dynamic eccentric data

250 analysis revealed a significant difference between $\operatorname{arcs}(P=0.02$, Figure 1$)$. Correcting

251 for multiple comparisons between the four arcs, there was only one pairwise comparison

252 to reach significant difference. The arc of Internal Rotation $25-50^{\circ}$ percent change score

253 was found to be significantly greater than the arc of Internal Rotation $0-25^{\circ}(P=0.007$,

254 Table 2). Following eccentric training the only arc of motion that had a positive

255 improvement in the capacity to absorb eccentric loads was the arc of motion that

256 represented eccentric contractions at the longest muscle length.

\section{DISCUSSION}

258

264 adaptation in serial sarcomere number in the vastus intermedius muscle. ${ }^{30}$ Although

265 fiber strains were not directly measured, it was reasonably assumed that the quadriceps

266 operated eccentrically during daily bouts of downhill walking, and eccentric training was

267 associated with a significant increase in fiber length and serial sarcomere number, and

268 therefore greater force at longer lengths. ${ }^{20,30}$ By directly measuring fiber dynamics,

269 Butterfield et al. associated positive active fiber strains to subsequent serial sarcomere 
270 number increases of $\sim 10 \%$ in the vastus intermedius after 10 days of eccentrically-

271 biased exercise. ${ }^{23}$ Subsequently it was shown that higher positive fiber strains during

272 eccentric exercise resulted in greater serial sarcomere number adaptations, and this

273 could be accomplished by exercising the muscle through excursions involving long

274 muscle lengths near or at terminal ranges of motion. ${ }^{50} 12$

275 Serial sarcomere number measurements, and therefore direct measurements of

276 sarcomerogenesis, are impractical, if not impossible in human subjects. Therefore,

277 architectural and functional measures previously associated with sarcomerogenesis in

278 animal models are used as indirect measures of a beneficial adaptation to eccentric

279 exercise in humans, including a rightward shift in the muscle's torque-joint angle

280 relationship, ${ }^{34,37}$ adaptations in muscle architecture such as longer muscle fibers, ${ }^{35,36,51}$

281 and/or increased fiber pennation angles. ${ }^{52}$

282 In this study, by training the posterior shoulder muscles eccentrically, we were

283 interested to see if changes in both isometric and dynamic eccentric strength of the

284 shoulder external rotators would increase the ability of the posterior shoulder

285 musculature to absorb eccentric loads at the end range of the eccentric motion. We

286 found that our eccentrically biased training program for the posterior shoulder muscles

287 did not have an effect on their isometric torque-joint angle relationship. Although a

288 rightward shift following repeated bouts of eccentric exercise training has been

289 associated with serial sarcomerogenesis in human muscle, ${ }^{37}$ there is evidence that

290 sarcomere number adaptations can also occur without a significant shift in this

291 relationship. Chen et al., found a direct association between training load and torque-

292 angle shift following eccentric exercise training in human subjects. ${ }^{34}$ In their study, only

293 subjects that performed eccentric exercises at $100 \%$ of maximal voluntary contraction

294 exhibited a rightward shift of the torque-angle curve on the biceps brachii, despite

295 additional groups that trained submaximally exhibiting other beneficial training 
296 adaptations such as the repeated bout effect, or resistance to subsequent eccentric

297 exercise-induced injury. ${ }^{34}$

298 It is therefore possible that our training program was not long enough or the

299 resistive load may not have been adequate to facilitate a measureable muscular

300 adaption in isometric torque. This is supported, in part, by the aforementioned eccentric

301 training studies in rabbits, whereby higher evoked forces during eight weeks of eccentric

302 training resulted in greater rightward shift of the torque-angle curves. ${ }^{12,50}$ In addition,

303 the lack of a shift in the isometric torque-angle relationship may be associated with the

304 methodology in calculating the angle of isometric peak torque production. ${ }^{53}$ By

305 necessity, the isometric torque measures in our study herein are discreet data points,

306 measured at every $15^{\circ}$ of glenohumeral rotation. Therefore, it is possible that changes

307 in isometric peak torque may have occurred between two discreet measurements.

308 Lastly, the torque-angle relationship is a measurement that is sensitive to several

309 factors, and easily altered by factors such as reduced effort, fatigue, alterations in series

310 compliance, and/or changes in muscle / tendon stiffness. ${ }^{53}$

311 Therefore, we also measured the dynamic eccentric torque-angle relationship as

312 a more robust indicator of the muscle's capacity for energy absorption. ${ }^{54,55}$ The

313 mechanism of force production during an eccentric contraction differs significantly from

314 the traditional mechanism of cross-bridge produced force during isometric and

315 concentric contractions. ${ }^{56-60}$ Therefore, forces produced eccentrically are independent of

316 fiber type ${ }^{61}$ and although fiber transitions can modify the muscle's contractile velocity,

317 power, and rate of force development during concentric contractions, their influence on

318 force is essentially eliminated during isometric contractions, when the velocity is zero. ${ }^{62}$

319 However, exercise-induced alterations in the elastic elements of the muscle and/or

320 tendon can modify force production. ${ }^{63,64}$ Elastic energy storage is an essential

321 component of the shoulder musculature for throwing activities ${ }^{65}$ and stiffening of the 
322 parallel elastic component of the muscle by itself or in conjunction with

323 sarcomerogenesis could explain our results. The increase in angular impulse at the

324 longest muscle length is a significant adaptation to eccentrically biased exercise. It can

325 be produced by increasing the length of the muscle fibers ${ }^{20}$, is indicative of serial

326 sarcomere number increases ${ }^{11,12}$, and it increases the amount of energy that the

327 external rotators can absorb while actively lengthening, ${ }^{3,66}$ and reduces the potential for

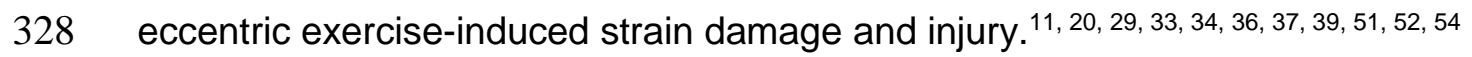

329 It is well documented that the posterior shoulder needs to act eccentrically to

330 decelerate the arm during the termination of a baseball pitch, tennis serve or similar

331 movement. ${ }^{67-70}$ We believe the ability to effectively activate the posterior shoulder

332 musculature eccentrically through the full range of motion is critical for avoiding injuries

333 in the shoulder, specifically for overhead throwing athletes. Although our subjects

334 performed the testing and exercise procedures with the shoulder in a different position

335 compared to that of a throwing motion, we propose that the functional adaptations

336 measured in this study are translatable. The posterior shoulder musculature must

337 decelerate the shoulder during both the deceleration phase and the follow-through

338 phase of pitching, as the loads are dissipated. Fleisig et al., calculated a significant

339 internal rotation torque at the shoulder that was still evident at terminal internal rotation. ${ }^{69}$

340 At the time of ball release, Werner et al., calculated high distraction forces that were

341 dissipated over course of the following $200 \mathrm{~ms}^{71,72}$, as the shoulder continues to

342 internally rotate to approximately $0^{\circ}$ of glenohumeral rotation. ${ }^{73}$

\section{$344 \quad$ Limitations}

345 We used two different positions for exercising and testing the muscles of the

346 posterior shoulder. It is reasonable to expect that exercise-induced adaptations in

347 skeletal muscle to be specific function; i.e. contraction type and muscle length. 
348 Therefore, it is possible that the exact magnitude of the adaptations were not measured

349 due to the different position of testing. However, we did find an improved eccentric

350 impulse at long muscle lengths for the posterior shoulder musculature in a shoulder

351 position (and muscle position), which indicates the robustness of the adaptation at the

352 tissue level. Future studies will utilize a laboratory setting to test and measure in

353 identical positions.

354 It is possible that adaptations in motor unit recruitment occurred in our subjects

355 over the course of the study. However, the lack of a significant training effect in the

356 isometric torque data in conjunction with the systematic improvement in eccentric torque

357 production in only the terminal arc of motion makes this less likely. In addition, muscle

358 morphological and functional adaptations to eccentric loading are evident earlier

359 compared to adaptations from isometric and concentric training, which supports fiber

360 adaptation following a short, eccentrically-biased, four week training program. ${ }^{74}$ In future

361 studies measuring eccentric exercise-induced adaptations in our laboratory, we will

362 include longer exercise durations and higher intensities, incorporate methods to assess

363 muscle activation such as EMG, and measure rate of torque development and muscle

364 stiffness to further separate viable mechanisms underlying the functional adaptations in

365 skeletal muscle.

366

367 Conclusion

368 In this pilot study, we have shown for the first time that an eccentrically-biased

369 home exercise program can improve the energy absorption capacity of the posterior

370 shoulder muscles by increasing the eccentric torque production at terminal internal

371 rotation. The exercises performed in this study can be translated easily for clinical use

372 by overhead athletes. While these exercises do not approach the velocity seen in

373 overhead sports, they could be good options for training program for overhead athletes 
374 or during rehabilitation to facilitate eccentric strengthening of the posterior shoulder

375 musculature. The two posterior shoulder eccentric exercises used during this six week

376 intervention appear to support the concept of specific adaptation to imposed demand

377 principle and increases the ability to absorb forces with the muscle in a lengthened

378 position. 
380 Table 1. Isometric Change scores

\begin{tabular}{lcc}
\hline \multicolumn{2}{c}{ Median Change } & Interquartile Range \\
& Score & \\
\hline External Rotation 15 & 4.79 & $(-5.6-11.4 \%)$ \\
Neutral 0 & 1.18 & $(-5.1-21.6 \%)$ \\
Internal Rotation 15 & 7.75 & $(-10.4-26.5 \%)$ \\
Internal Rotation 30 & -1.91 & $(-2.9-17.8 \%)$ \\
Internal Rotation $45^{\circ}$ & 1.64 & $(-1.2-17.4 \%)$
\end{tabular}

381 (-) indicates that the isometric strength decreased from baseline value 382

383 
385 Table 2. Dynamic Eccentric Percent Change Scores compared to the longest position of 386 Internal Rotation arc 25-50

\begin{tabular}{lcccc}
\hline & Short & & & Long \\
& External & External & Internal & Internal \\
& Rotation & Rotation & Rotation & Rotation \\
& $50-25^{\circ}$ & $25-0^{\circ}$ & $0-25^{\circ}$ & $25-50^{\circ}$ \\
\hline Median Change Scores & -3.4 & -3.0 & +0.4 & +9.5 \\
Interquartile Range & $(-21.8-12.7)$ & $(-14.1-7.9)$ & $(-8.9-12.9)$ & $(2.2-31.0)$ \\
Significance & $P=0.059$ & $P=0.017$ & $P=0.007^{*}$ & \\
Compared to Long IR 25-50 & & & \\
\hline * Indicates that change scores is significantly different from Internal Rotation $25-50^{\circ}$
\end{tabular}


$390 \quad$ Figure 1

Angular Impulse by Arcs of Motion

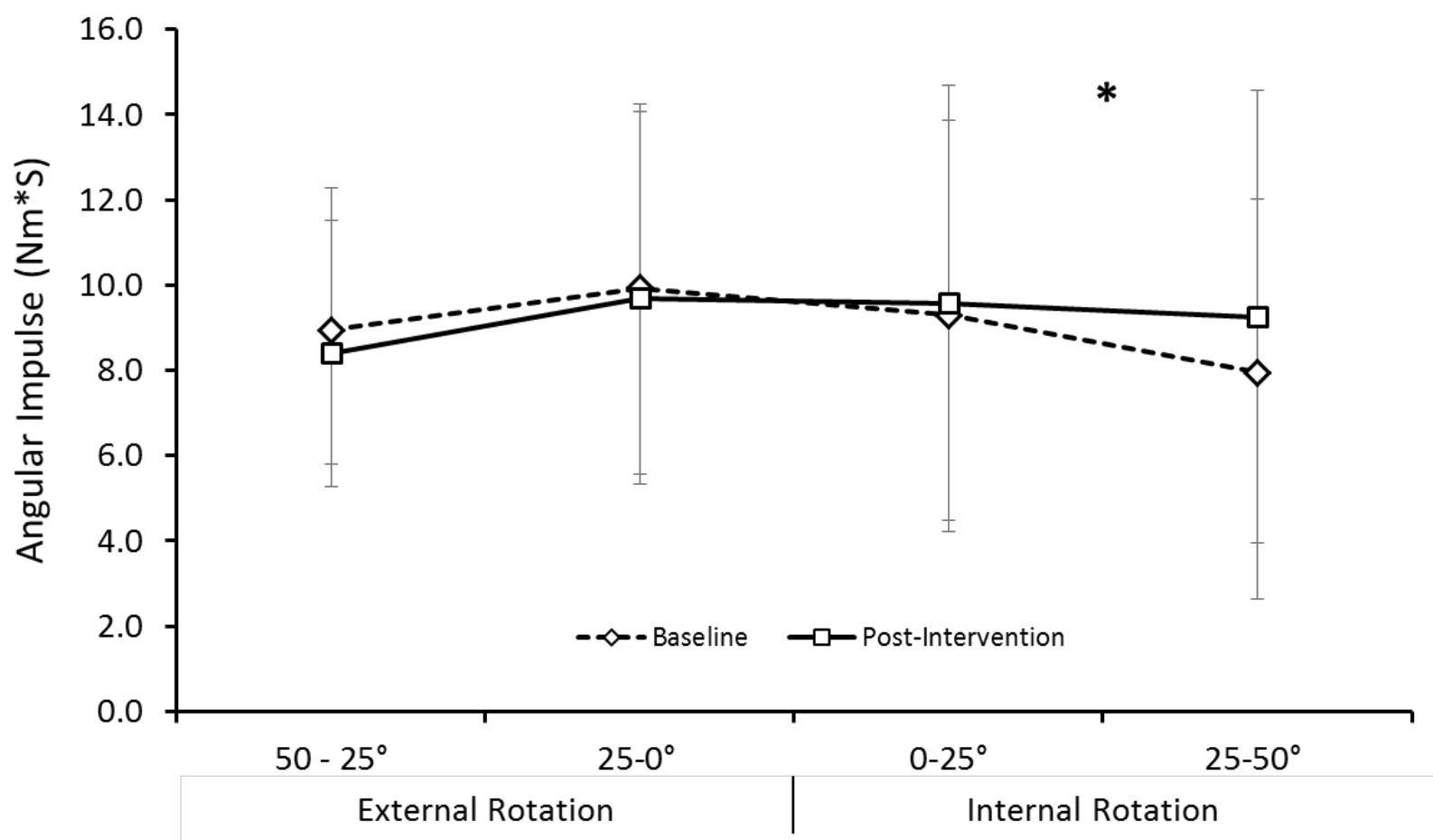

391 
392 Figure captions

393

394 Figure 1. Mean eccentric angular impulse for the posterior shoulder muscles on day 1

395 (open triangles) and following and eccentrically biased training program (open squares)

396 for four arcs of motion. Eccentric contractions began with the posterior shoulder muscles

397 at their shortest length ( $50^{\circ}$ of external rotation) and the muscles were lengthened during

398 contraction to their longest lengths (50 internal rotation). Following eccentrically biased

399 training, the area under the eccentric torque-angle curve (angular impulse) was

400 significantly greater $\left(^{*}\right)$ for the arc of motion that represented the longest muscle lengths $401 \quad\left(25-50^{\circ}\right.$ internal rotation). 
1. Vanrenterghem J, Nedergaard NJ, Robinson MA, Drust B. Training Load Monitoring in Team Sports: A Novel Framework Separating Physiological and Biomechanical Load-Adaptation Pathways. Sports Med. 2017.

2. Clarkson PM, Nosaka K, Braun B. Muscle function after exercise-induced muscle damage and rapid adaptation. Med Sci Sports Exerc. 1992;24(5):512-520.

3. Butterfield TA. Eccentric exercise in vivo: strain-induced muscle damage and adaptation in a stable system. Exerc Sport Sci Rev. 2010;38(2):51-60.

4. Simoneau JA, Lortie G, Boulay MR, Marcotte M, Thibault MC, Bouchard C. Human skeletal muscle fiber type alteration with high-intensity intermittent training. Eur J Appl Physiol Occup Physiol. 1985;54(3):250-253.

5. $\quad$ Fry AC. The role of resistance exercise intensity on muscle fibre adaptations. Sports Med. 2004;34(10):663-679.

6. Blazevich AJ, Gill ND, Zhou S. Intra- and intermuscular variation in human quadriceps femoris architecture assessed in vivo. J Anat. 2006;209(3):289-310.

7. Petersen W, Taheri P, Forkel P, Zantop T. Return to play following ACL reconstruction: a systematic review about strength deficits. Arch Orthop Trauma Surg. 2014;134(10):1417-1428.

8. Fluck M, Waxham MN, Hamilton MT, Booth FW. Skeletal muscle $\mathrm{Ca}(2+)-$ independent kinase activity increases during either hypertrophy or running. J Appl Physiol (1985). 2000;88(1):352-358.

9. Nader GA, McLoughlin TJ, Esser KA. mTOR function in skeletal muscle hypertrophy: increased ribosomal RNA via cell cycle regulators. Am J Physiol Cell Physiol. 2005;289(6):C1457-1465.

10. Esser K. Regulation of mTOR signaling in skeletal muscle hypertrophy. $J$ Musculoskelet Neuronal Interact. 2008;8(4):338-339.

11. Proske U, Morgan DL. Muscle damage from eccentric exercise: mechanism, mechanical signs, adaptation and clinical applications. J Physiol. 2001;537(Pt 2):333-345.

12. Butterfield TA, Herzog W. The magnitude of muscle strain does not influence serial sarcomere number adaptations following eccentric exercise. Pflugers Arch. 2006;451(5):688-700.

13. De Deyne PG. Formation of sarcomeres in developing myotubes: role of mechanical stretch and contractile activation. Am J Physiol Cell Physiol. 2000;279(6):C1801-1811.

14. Hofmann WW. Mechanisms of muscular hypertrophy. J Neurol Sci. 1980;45(23):205-216.

15. Koh TJ, Herzog W. Eccentric training does not increase sarcomere number in rabbit dorsiflexor muscles. J Biomech. 1998;31(5):499-501.

16. Koh TJ, Herzog W. Excursion is important in regulating sarcomere number in the growing rabbit tibialis anterior. $J$ Physiol. 1998;508 ( Pt 1):267-280.

17. Burkholder TJ. Age does not influence muscle fiber length adaptation to increased excursion. J Appl Physiol (1985). 2001;91(6):2466-2470. 
18. Burkholder TJ, Lieber RL. Sarcomere number adaptation after retinaculum

19. Williams PE, Goldspink G. Longitudinal growth of striated muscle fibres. J Cell Sci. 1971;9(3):751-767.

20. Lynn R, Talbot JA, Morgan DL. Differences in rat skeletal muscles after incline and decline running. J Appl Physiol (1985). 1998;85(1):98-104.

21. Tabary JC, Tabary C, Tardieu C, Tardieu G, Goldspink G. Physiological and structural changes in the cat's soleus muscle due to immobilization at different lengths by plaster casts. J Physiol. 1972;224(1):231-244.

22. Tabary JC, Tardieu C, Tabary C, Lombard M, Gagnard L, Tardieu G. [Neural regulation and adaptation of the number of sarcomeres of the muscle fiber to the length imposed upon it]. J Physiol (Paris). 1972;65:Suppl 1:168A.

23. Butterfield TA, Leonard TR, Herzog W. Differential serial sarcomere number adaptations in knee extensor muscles of rats is contraction type dependent. J Appl Physiol (1985). 2005;99(4):1352-1358.

24. Tardieu C, Tabary JC, Gagnard L, Lombard M, Tabary C, Tardieu G. [Change in the number of sarcomeres and in isometric tetanic tension after immobilization of the cat anterior tibialis muscle at different lengths]. $J$ Physiol (Paris). 1974;68(2):205-218.

25. Williams PE, Goldspink G. The effect of immobilization on the longitudinal growth of striated muscle fibres. J Anat. 1973;116(Pt 1):45-55.

26. Tabary JC, Tardieu C, Tardieu G, Tabary C, Gagnard L. Functional adaptation of sarcomere number of normal cat muscle. J Physiol (Paris). 1976;72(3):277-291.

27. Woledge RC, Curtin NA, Homsher E. Energetic aspects of muscle contraction. Monogr Physiol Soc. 1985;41:1-357.

28. Goldspink G. Malleability of the motor system: a comparative approach. J Exp Biol. 1985;115:375-391.

29. Friden J. Changes in human skeletal muscle induced by long-term eccentric exercise. Cell Tissue Res. 1984;236(2):365-372.

30. Lynn R, Morgan DL. Decline running produces more sarcomeres in rat vastus intermedius muscle fibers than does incline running. J Appl Physiol (1985). 1994;77(3):1439-1444.

31. Butterfield TA, Best TM. Stretch-activated ion channel blockade attenuates adaptations to eccentric exercise. Med Sci Sports Exerc. 2009;41(2):351-356.

32. Herring SW, Grimm AF, Grimm BR. Regulation of sarcomere number in skeletal muscle: a comparison of hypotheses. Muscle Nerve. 1984;7(2):161-173.

33. Philippou A, Bogdanis GC, Nevill AM, Maridaki M. Changes in the angle-force curve of human elbow flexors following eccentric and isometric exercise. Eur $J$ Appl Physiol. 2004;93(1-2):237-244.

34. Chen TC, Nosaka K, Sacco P. Intensity of eccentric exercise, shift of optimum angle, and the magnitude of repeated-bout effect. J Appl Physiol (1985). 2007;102(3):992-999.

35. Lau WY, Blazevich AJ, Newton MJ, Wu SS, Nosaka K. Reduced muscle lengthening during eccentric contractions as a mechanism underpinning the repeated-bout effect. Am J Physiol Regul Integr Comp Physiol. 2015;308(10):R879-886. 
36. Potier TG, Alexander CM, Seynnes OR. Effects of eccentric strength training on biceps femoris muscle architecture and knee joint range of movement. Eur J Appl Physiol. 2009;105(6):939-944.

37. Brockett CL, Morgan DL, Proske U. Human hamstring muscles adapt to eccentric exercise by changing optimum length. Med Sci Sports Exerc. 2001;33(5):783-790.

38. Brughelli M, Nosaka K, Cronin J. Application of eccentric exercise on an Australian Rules football player with recurrent hamstring injuries. Phys Ther Sport. 2009;10(2):75-80.

39. McHugh MP, Tetro DT. Changes in the relationship between joint angle and torque production associated with the repeated bout effect. J Sports Sci. 2003;21(11):927-932.

40. Kibler WB, Kuhn JE, Wilk K, et al. The disabled throwing shoulder: spectrum of pathology-10-year update. Arthroscopy. 2013;29(1):141-161 e126.

41. Leggin BG, Michener LA, Shaffer MA, Brenneman SK, Iannotti JP, Williams GR, Jr. The Penn shoulder score: reliability and validity. J Orthop Sports Phys Ther. 2006;36(3):138-151.

42. Papotto BM, Rice T, Malone T, Butterfield T, Uhl TL. Reliability of Isometric and Eccentric Isokinetic Shoulder External Rotation. J Sport Rehabil. 2016;Technical Report.

43. Maganaris CN, Baltzopoulos V, Sargeant AJ. Repeated contractions alter the geometry of human skeletal muscle. J Appl Physiol (1985). 2002;93(6):20892094.

44. Rassier DE. The effects of length on fatigue and twitch potentiation in human skeletal muscle. Clin Physiol. 2000;20(6):474-482.

45. McNair PJ. Verbal encouragement of voluntary muscle action: reply to commentary by Roger Eston. Br J Sports Med. 1996;30(4):365.

46. Lagasse PP, Katch FI, Katch VL, Roy MA. Reliability and validity of the Omnitron hydraulic resistance exercise and testing device. Int J Sports Med. 1989;10(6):455-459.

47. Mayer F, Horstmann T, Kranenberg U, Rocker K, Dickhuth HH. Reproducibility of isokinetic peak torque and angle at peak torque in the shoulder joint. Int $J$ Sports Med. 1994;15 Suppl 1:S26-31.

48. Blackburn TA, MacLeod WD, WHite B, Wofford L. EMG analysis of posterior rotator cuff exercises. Journal of Athletic Training. 1990;25:5.

49. Friden J, Seger J, Sjostrom M, Ekblom B. Adaptive response in human skeletal muscle subjected to prolonged eccentric training. Int J Sports Med. 1983;4(3):177-183.

50. Butterfield TA, Herzog W. Effect of altering starting length and activation timing of muscle on fiber strain and muscle damage. J Appl Physiol (1985). 2006;100(5):1489-1498.

51. Baroni BM, Geremia JM, Rodrigues R, De Azevedo Franke R, Karamanidis K, Vaz MA. Muscle architecture adaptations to knee extensor eccentric training: rectus femoris vs. vastus lateralis. Muscle Nerve. 2013;48(4):498-506.

52. Blazevich AJ, Cannavan D, Coleman DR, Horne S. Influence of concentric and eccentric resistance training on architectural adaptation in human quadriceps muscles. J Appl Physiol (1985). 2007;103(5):1565-1575. 
53. Butterfield TA, Herzog W. Is the force-length relationship a useful indicator of contractile element damage following eccentric exercise? J Biomech. 2005;38(9):1932-1937.

54. Lindstedt SL, LaStayo PC, Reich TE. When active muscles lengthen: properties and consequences of eccentric contractions. News Physiol Sci. 2001;16:256-261.

55. Kaminski TW, Wabbersen CV, Murphy RM. Concentric versus enhanced eccentric hamstring strength training: clinical implications. J Athl Train. 1998;33(3):216-221.

56. Herzog W. The role of titin in eccentric muscle contraction. J Exp Biol. 2014;217(Pt 16):2825-2833.

57. Herzog W. Mechanisms of enhanced force production in lengthening (eccentric) muscle contractions. J Appl Physiol (1985). 2014;116(11):1407-1417.

58. Herzog W, Leonard T, Joumaa V, DuVall M, Panchangam A. The three filament model of skeletal muscle stability and force production. Mol Cell Biomech. 2012;9(3):175-191.

59. Hoppeler H, Herzog W. Eccentric exercise: many questions unanswered. J Appl Physiol (1985). 2014;116(11):1405-1406.

60. Schappacher-Tilp G, Leonard T, Desch G, Herzog W. A novel three-filament model of force generation in eccentric contraction of skeletal muscles. PLoS One. 2015;10(3): 0117634.

61. Hortobagyi T, Zheng D, Weidner M, Lambert NJ, Westbrook S, Houmard JA. The influence of aging on muscle strength and muscle fiber characteristics with special reference to eccentric strength. J Gerontol A Biol Sci Med Sci. 1995;50(6):B399-406.

62. Komi PV. Training of muscle strength and power: interaction of neuromotoric, hypertrophic, and mechanical factors. Int J Sports Med. 1986;7 Suppl 1:10-15.

63. Magnusson SP, Narici MV, Maganaris CN, Kjaer M. Human tendon behaviour and adaptation, in vivo. $J$ Physiol. 2008;586(1):71-81.

64. Urlando A, Hawkins D. Achilles tendon adaptation during strength training in young adults. Med Sci Sports Exerc. 2007;39(7):1147-1152.

65. Roach NT, Venkadesan M, Rainbow MJ, Lieberman DE. Elastic energy storage in the shoulder and the evolution of high-speed throwing in Homo. Nature. 2013;498(7455):483-486.

66. Garrett WE, Jr., Safran MR, Seaber AV, Glisson RR, Ribbeck BM. Biomechanical comparison of stimulated and nonstimulated skeletal muscle pulled to failure. Am J Sports Med. 1987;15(5):448-454.

67. Ellenbecker TS, Davies GJ, Rowinski MJ. Concentric versus eccentric isokinetic strengthening of the rotator cuff. Objective data versus functional test. Am $J$ Sports Med. 1988;16(1):64-69.

68. Escamilla RF, Andrews JR. Shoulder muscle recruitment patterns and related biomechanics during upper extremity sports. Sports Med. 2009;39(7):569-590.

69. Fleisig GS, Andrews JR, Dillman CJ, Escamilla RF. Kinetics of baseball pitching with implications about injury mechanisms. Am J Sports Med. 1995;23(2):233239.

70. Jobe FW, Tibone JE, Perry J, Moynes D. An EMG analysis of the shoulder in throwing and pitching. A preliminary report. Am J Sports Med. 1983;11(1):3-5. 
71. Werner SL, Guido JA, Delude NA, Stewart GW, Greenfield JH, Meister K. Throwing arm dominance in collegiate baseball pitching: a biomechanical study. Am J Sports Med. 2010;38(8):1606-1610.

588 72. Werner SL, Suri M, Guido JA, Jr., Meister K, Jones DG. Relationships between ball velocity and throwing mechanics in collegiate baseball pitchers. J Shoulder Elbow Surg. 2008;17(6):905-908.

592

593

594

595

73. Dillman CJ, Fleisig GS, Andrews JR. Biomechanics of pitching with emphasis upon shoulder kinematics. J Orthop Sports Phys Ther. 1993;18(2):402-408.

74. Douglas J, Pearson S, Ross A, McGuigan M. Eccentric Exercise: Physiological Characteristics and Acute Responses. Sports Med. 2016. 
Appendix

Side-lying Eccentric Horizontal Adduction

1) Lie on your back near the edge of a firm surface; preferably the floor or a firm mattress. (Figure 1)

2) Extend the non-exercising arm straight up in the air while holding the weight. (Figure 2)

3) Extend your exercising arm straight up in the air, transfer the weight to the opposite (exercising) hand and drop your non-exercising hand to your side. (Figures 3-5)

4) Roll on to your non-exercising side keeping the weight still extended straight up in the air. (Figure 6)

5) Now, using an 8 count, slowly lower the weight, keeping your thumb pointing towards the ceiling, your arm straight, and your arm in-line with your mouth. (Figures 7-8)

6) Let the weight lower as far as the surface will permit, hanging off if possible (Figure 8)

7) Once the weight has been fully lowered, roll on to your back (Figure 9) and assume the starting position. (Figure 1) Repeat the steps for 2 sets of 15 repetitions.

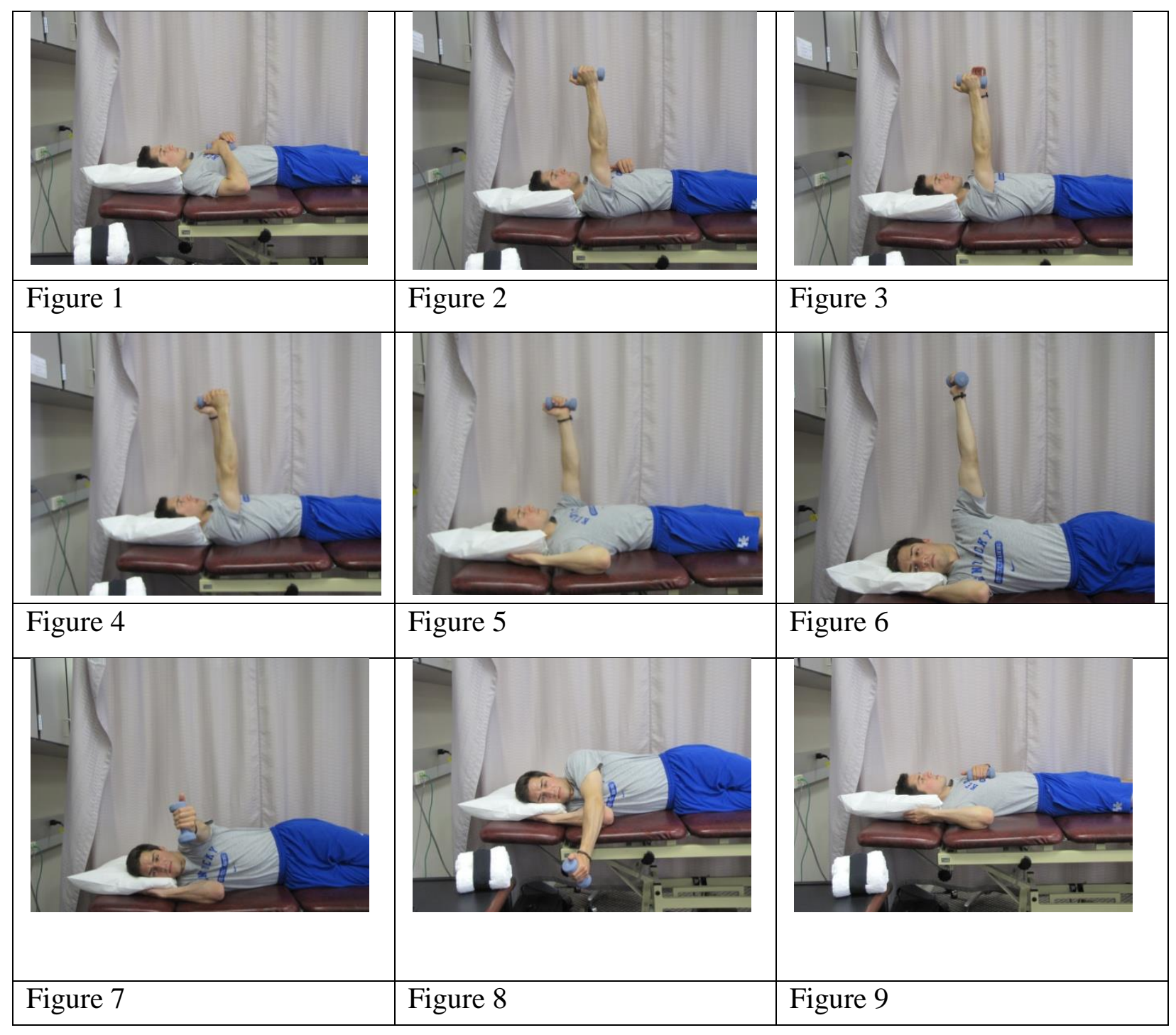


Side-Lying Eccentric External Rotation

1) Lie on your side on a firm surface, with a rolled up towel or bolster placed under your arm, with the weight held by your non-exercising arm as shown. (Figure 1)

2) Roll onto your back and bring the weight up to your exercising arm, making sure to keep the towel under your arm. (Figure 2)

3) Roll back on to your side, your arm should rotate up towards the ceiling. (Figure 3)

4) Slowly lower the weight towards the surface, keeping the elbow bent at a right angle. (Figures 4-6)

5) Once you have gone through your available range of motion, drop the weight to the surface. (Figure 7)

6) With the non-exercising arm, pick up the weight. (Figure 8) and position your arm back in the starting position to repeat the exercise for the given number of repetitions. (Figures 9, 1)

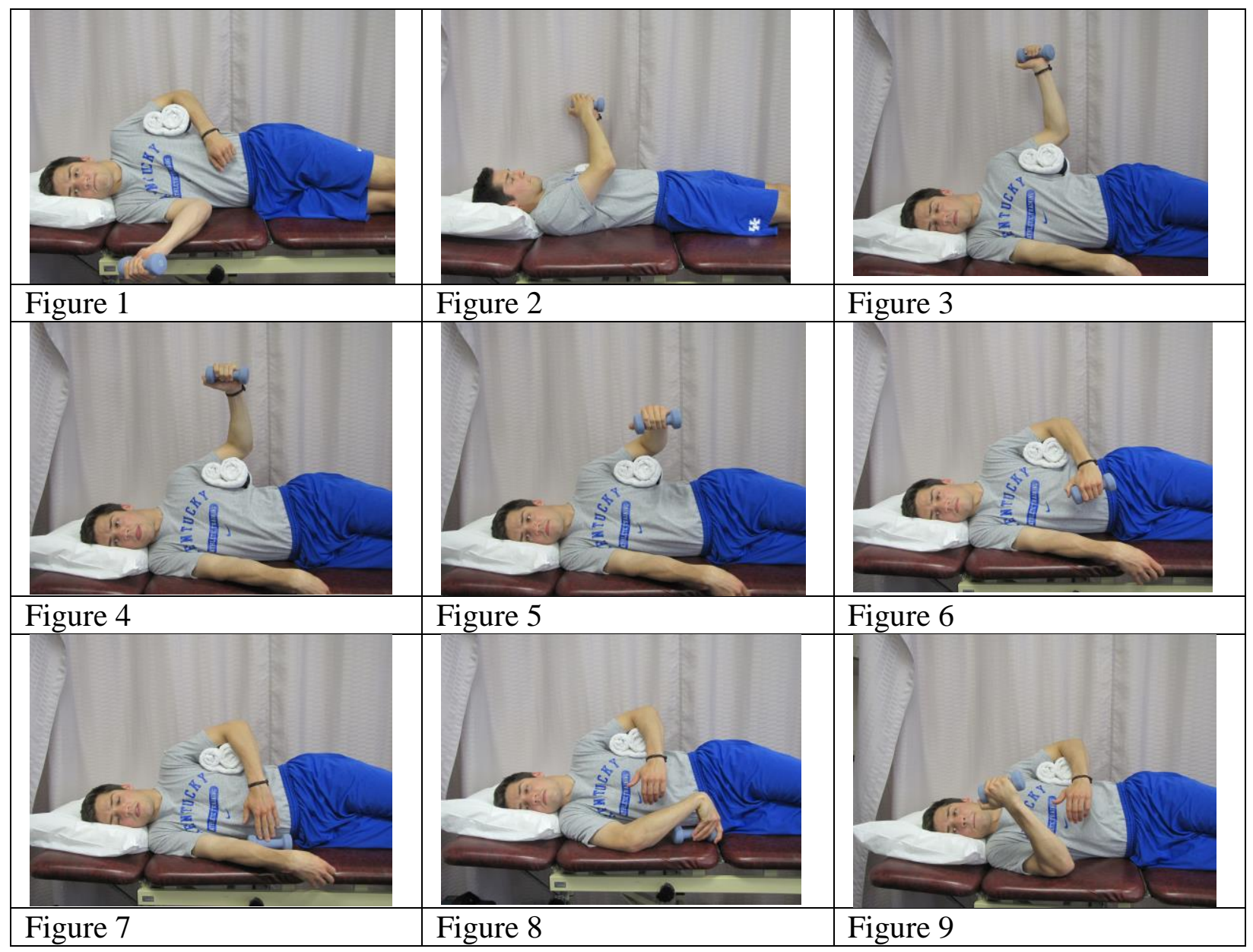

